\title{
Comparison Analysis of Zeta PFC Converter to Improve Power Quality Improvement by PI Controller, Hysteresis Controller and Fuzzy Logic Controller for Speed Control of Induction Motor
}

\author{
V.Satya Narayana ${ }^{1}$, J.N.Chandrasekhar ${ }^{2}$ \\ ${ }^{I}$ P.G. Student, Department of Electrical \& Electronics, SV University, Tirupati, Andhra Pradesh, India \\ ${ }^{2}$ Assistant Professor, Department of Electrical \& Electronics, SV University, Tirupati, Andhra Pradesh, India
}

\begin{abstract}
This project "comparison analysis of ZETA PFC converter to improve power quality improvement by PI Controller, Hysteresis controller and Fuzzy logic controller for speed control of a Induction Motor"is composed of anisolated ZETA converter is proposed as a power factor correction (PFC) converter with DC link voltage control for speed control of a Induction Motor (IM).Induction motor has got the volatility of wide range of speed control.Power electronic converters canenvisage dynamic speed control. The front end rectifier and dc to dc converter can be monitored to facilitate requisiteinput voltage to the inverter fed drive working at constant speed. A single phase supply followed by an uncontrolledbridge rectifier and a Zeta DC-DC converter is used to control the voltage of a DC link capacitor which is lying between the Zeta converter and a Voltage Source Inverter (VSI). Speed control is achieved by maintaining constant dclink voltage. In this drive, speed is controlled by adjusting the DC link voltage of the VSI feeding induction motor.VSI operates in a low frequency switching mode for reduced switching losses. The voltage source inverter (VSI) is used as a stator supply of Induction Motor. The proposed converter performs the PFC action and DC link voltage control in single stage using only one controller. The current multiplier approach with average current control is used for operation of the isolated ZETA converter in continuous conduction mode $(C C M)$. A rate limiter in the reference DC link voltage is designed for the control of current and torque in Induction Motor. The designed PFC converter results in an improved power quality at AC mains in a wide range of speed control and input AC voltage.
\end{abstract}

\section{Introduction}

Variable frequency drives are increasingly more hired in business and traction functions. The masses connected are constantly various disturbing speed control over wide variety..Induction motor is referred as 'work horse' of enterprise because of its extensive type of applications in industry. Be it home applications or enterprise, motion manipulate is required anywhere. A device that uses electric automobiles is known as an electrical force. In electrical drives, use of numerous sensors and manage algorithms is performed to manipulate the speed of the motor the use of suitable speed manage techniques. Induction motors are the most broadly used cars for appliances, industrial manage, and automation, therefore, they're regularly called the workhorse of the motion industry. [1] They're strong, dependable, and sturdy. Whilst energy is supplied to an induction motor at the elective specs, it runs at its rated speed. but, many packages want variable speed operations power system face lot of power exceptional issues like harmonics, the complex dynamics of ac machines, gadget parameter version, and the difficulties of processing remarks alerts within the presences of harmonics negative power thing, noise, negative starting situations and so on. Strength electronic converters are hired to improve the first-rate of electricity furnished to the pressure systems. Induction motor when fed with the aid of an out of control bridge rectifier with DC hyperlink capacitor effects in relatively distorted deliver cutting-edge which ends up in low PF (strength element) and high general Harmonic Distortion (THD), hence diverse stepped forward energy fine AC-DC converters are used in these force level percent converters are widely in practice wherein first stage is used for the electricity thing correction that is preferably a lift converter and $2 \mathrm{~d}$ level for voltage law which can be any converter topology depending upon the requirement. Conventionally modern multiplier approach is employed in continuous Conduction Mode (CCM), a voltage follower require simplest single sensor for voltage law. The sensing gadgets provide position feedback for adjusting frequency and amplitude of stator voltage reference well to keep rotation of the magnet assembly. The scheme discussed in this paper maintains excessive power factor and low THD of the AC source modern-day whilst controlling rotor velocity equal to the set reference velocity. A voltage follower method is used for the manage of ZETA DC-DC converter operation. The DC link voltage is controlled by way of a single voltage sensor. Sensed DC hyperlink voltage ( $\mathrm{Vdc}$ ) is as compared with reference link voltage $\left(\mathrm{Vdc}^{*}\right)$ to generate an errors signal that's the difference of $\mathrm{Vdc}^{*}$ and $\mathrm{Vdc}$. The mistake signal is given to a PI (Proportional crucial) controller to present a controlled output. In the end, the managedoutput is compared with the excessive frequency noticed enamel sign to generate PWM (Pulse Width Modulation) pulse for the MOSFET of the ZETA converter. A charge limiter is used to limit the stator modern-day at some stage in step exchange in speed. [2]. 


\section{Volts Per Hertz Control Of Induction Motor}

Synchronous speed can be controlled by way of varying the supply frequency. Voltage brought about in the stator is given in (1)

$\mathrm{E}_{1} \alpha \emptyset f(1)$

where $\emptyset$ is flux and $f$ is frequency. On neglecting the stator voltage drop then terminal voltage is given as $\mathrm{V}_{1} \propto \emptyset f(2)$

as a result decreasing the frequency without changing the deliver voltage will cause an boom inside the air-gap flux that isundesirable. As a result on every occasion frequency is numerous to be able to manage velocity, the terminal voltage is likewise varied so one canhold the $V / f$ ratio constant. by retaining a steady $V /$ $f$ ratio, the maximum torque of the motor will becomeconsistent for changing speed. As may be visible, while $V / f$ manage is carried out, for numerous frequencies in therunning place, the maximum torque stays the same as the rate varies. for this reason, maintaining the $V / f$ ratio steadyhelps us to maintain a steady most torque whilst controlling the rate as consistent with our requirement. Volts per hertzmanage may be carried out in two methods, they're described underneath.

\section{Linecurrent}

The input current increases linearly according the followingequation:

$i_{\text {in }}(t)=\frac{V_{p} \sin (w t)}{L} t$

If weconsider an input filter to eliminate the high frequencyharmonics,thus:

$i_{\text {in }}(t)=\frac{V_{p} \cdot D}{L \cdot f s} \sin (w t)$

So,theinputcurrentisasinusoidal curvewithunitypower factor.

Outputcharacteristic $(\mathrm{G})$

$\mathrm{G}=\frac{V_{O}}{V_{P}}=\frac{D}{2} \sqrt{\frac{R_{O}}{L \cdot f s}}$

\section{a) Open loop v/f control}

The open loop V/F control of an induction motor is the most common approach of speed manage due to its simplicityand those types of automobiles are extensively used in enterprise. Historically, induction vehicles have been used with open loop, $50 \mathrm{~Hz}$ strength materials for regular velocity programs [3].For adjustable speed power packages, frequency control is natural. But, voltage is required to be proportional to frequency so that the stator flux stays regular if the stator resistance is left out. The power circuit consists of a diode rectifier with a single or 3-phase ac supply, filter out and PWM voltage-fed inverter. Ideally no comments indicators are required for this manage scheme. The PWM converter is merged with the inverter block.[4] Block diagram of open loop manage is proven in fig 1

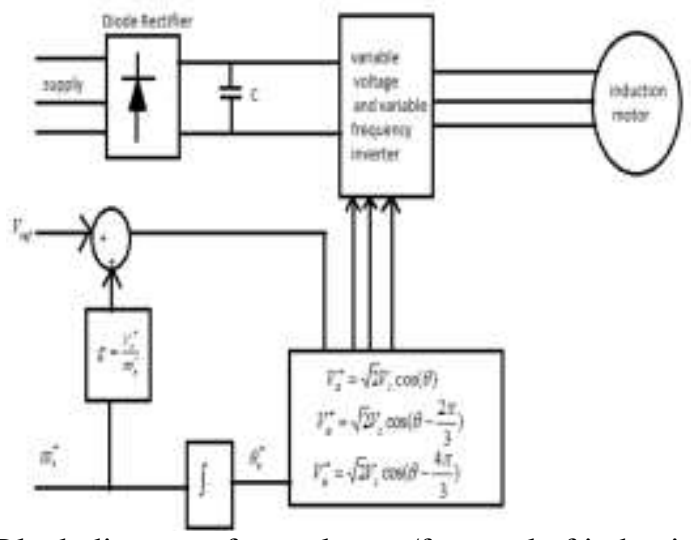

Fig 1: Block diagram of open loop v/f control of induction motor

The speed of the motor cannot be managed precisely, due to the fact the rotor speed will be slightly much less than thesynchronous speed and that in this scheme the stator frequency and hence the synchronous speed is the handiest manage variable. The slip velocity, being the distinction among the synchronous speed and the electric rotor speed, cannot be maintained, because the rotor velocity is not measured on this scheme. This will lead to operation in the volatile location of the torque-speed characteristics. [5] The effect of the above could make the stator currents exceed the rated modern-day by a huge quantity therefore endangering the inverter converter mixture. 


\section{(b) Closed Loop $v / f$ system}

The demerits of open loop are to be suppress via having an outer loop inside the induction motor force, in which the actual rotor speed is as compared with its commanded fee, and the mistake is processed via a controller typically a PI controller and a limiter is used to achieve the slip-speed command [6] .A speed sensor or a shaft role encoder is used to acquire the real speed of the motor. It's miles then as compared to a reference velocity. The distinction between the two generates an error and the error so received is processed in a Proportional controller and its output sets the inverter frequency. The synchronous velocity, received by way of including real speed and the slip speed determines the inverter frequency. The reference sign for the closed-loop manipulate of the machine terminal voltage. Block diagram of closed loop manage is given in fig.2. In regular $V / f$ manipulate, by using use of rectifier and PWM inverter, we will range the deliver voltage in addition to the supply frequency such that the ratio remains constant so that the flux remains steady too. So we will get exclusive working sector for various speeds and torques and also we can get distinct synchronous speed with nearly identical most torque.

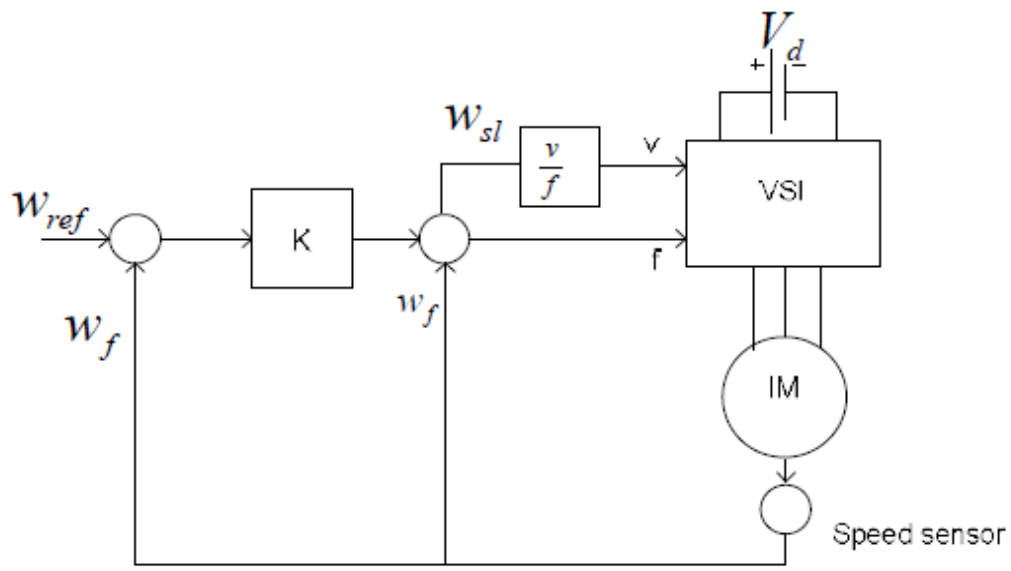

Fig 2: Block diagram of closed loop v/f control of induction motor

Thus the motor is absolutely applied and also we've an excellent variety of speed control. This paper affords a new approach of $V / f$ control, that's primarily based on present day feedback to improve the stability of the traditional $V / f$ control. The proposed approach is based totally at the stator present day derivatives. This new method has effectively dampedthe torque and speed oscillations in V/f control for low power IM force gadget. But, making use of this technique forexcessive voltage IM led to extra oscillations and result in a fantastically volatile power machine. This paper analyses the reasonsof this instability and proposes a damper to suppress the undesirable oscillations. The proposed damper is easy to put in force and facilitates do away with the oscillations which reasons the instability of V/f for excessive voltage IM.

\section{Zeta Converter Fed Induction Motor Drive Control}

The proposed scheme for the sensor much less induction motor force fed by a ZETA based totally percent converter works in DICM mode is shown in Fig. 3. The ZETA converter continues the DC link voltage to a sure set reference price. In ZETA converter the switching operation is completed at excessive switching frequency for powerful manipulate which ends up in the reduction of length of components like inductors. The detection of rotor position for electronic commutation is accomplished by using a sensor much less method. A blind startup is used for starting the induction motor. An appropriate MOSFET having a high frequency rating is used within the front end converter for its high frequency operation while for the low frequency operation ofVSI-IGBTsare used [7]. The proposed scheme keeps high strength aspect and coffee THD of the AC supply modern at the same time as controlling rotor velocity same to the set reference velocity. Right here the ZETA converter uses a voltage follower approach which is used for the manipulate the converter running in DICM. The DC link voltage is controlled by way of a single voltage sensor. $V_{d c}$ (sensed DC link voltage) is in comparison with $\mathrm{V}_{\mathrm{dc}} *$ (reference voltage) to generate an error sign which is the distinction of $\mathrm{V}_{\mathrm{dc}} *$ and $\mathrm{V}_{\mathrm{dc}}$. The error signal is given to a Proportional necessary (PI) controller to provide a controlled output.[8]. The controlled output is in comparison with the high frequency saw tooth signal to generate PWM pulse for the MOSFET of the ZETA converter. 


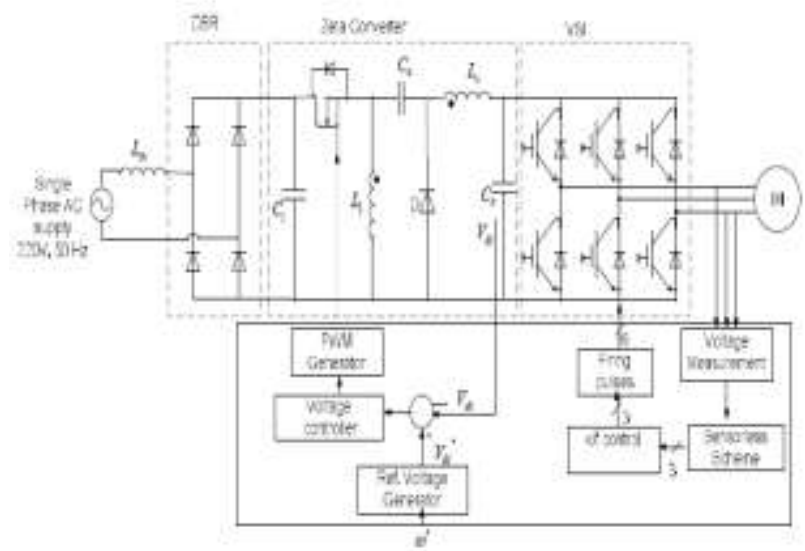

Fig 3: Block diagram of open loop v/f control of induction motor

\section{Operations of ZETA converter}
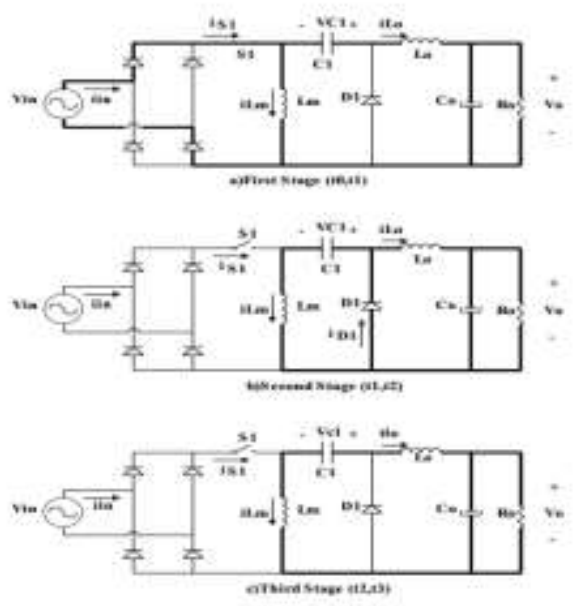

Fig 4: operation of ZETA converter with respect to time periods

\section{Theoretical waveforms}

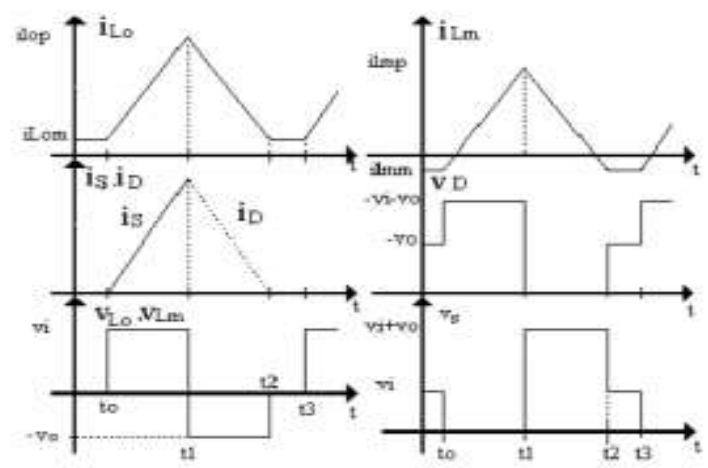

Fig 5:switching waveforms

\section{Methods Of Operation}

Fig. 5 demonstrates the circuit outline of a ZETA converter. It comprise of an information capacitor $\mathrm{C} 1$, a yield capacitor, $\mathrm{C} 0$, coupled inductors $\mathrm{L} 1$ and $\mathrm{L} 0$, an $\mathrm{AC}$ coupling capacitor, $\mathrm{Cu}$, a power MOSFET, S, and a diode, D. Fig.5a demonstrates the ZETA converter working in CCM when $S$ is on and fig. 5b demonstrates the ZETA converter working in CCM when turn is off. It is essential to investigate the circuit at DC when both changes are headed toward comprehend the voltages at the different [9] circuit hubs. $\mathrm{Cu}$ is charged to the yield voltage, Vo, amid unfaltering state CCM since Capacitor $\mathrm{Cu}$ is in parallel with Co. Figure 
5.2 demonstrates the waveforms of voltages crosswise over L1 and L1 amid CCM operation. At the point when $\mathrm{S}$ is off , I the voltage crosswise over L1 is Vo since it is in parallel with Co. The voltage crosswise over $\mathrm{S}$ when $\mathrm{S}$ is off is Vin $+\mathrm{Vo}$, in this manner the voltage crosswise over L1 is Vo in respect to the deplete of S. At the point when switch $\mathrm{S}$ is on, capacitor $\mathrm{Cu}$, charged to Vo, is associated in arrangement with L1, so the voltage crosswise over L1 is +Vin, and diode D sees Vin + Vo.[10].

\section{Mathematical expressions:}

The input current increases linearly according theFollowing equation:

$\mathrm{i}_{\text {in }}=\frac{v p \cdot \sin \omega t}{L} \cdot \mathrm{t}(3)$

Output characteristic $(\mathrm{G})$,

$\mathrm{G}=\frac{v o}{v p}=\frac{D}{2} \sqrt{\frac{R o}{L \cdot f s}}$

\section{Simulation And Results}

1 a)Simulink model of Closed loop system

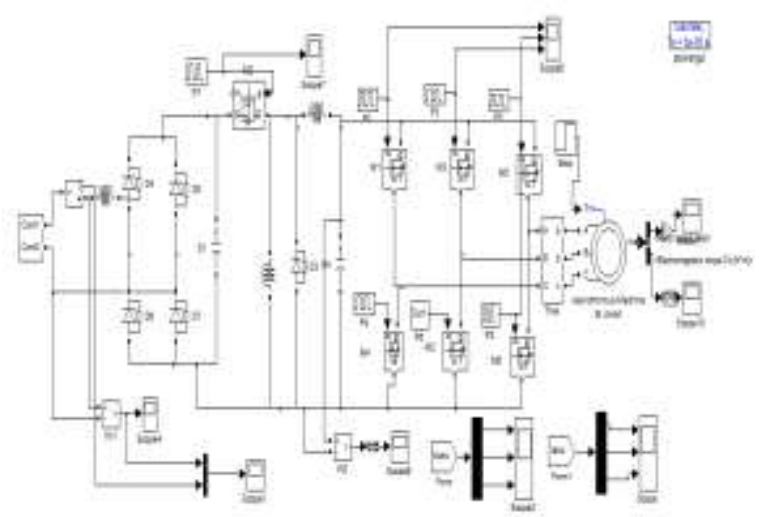

Fig 6: Simulink model of closed loop v/f control of induction motor

\section{1b)simulink results}

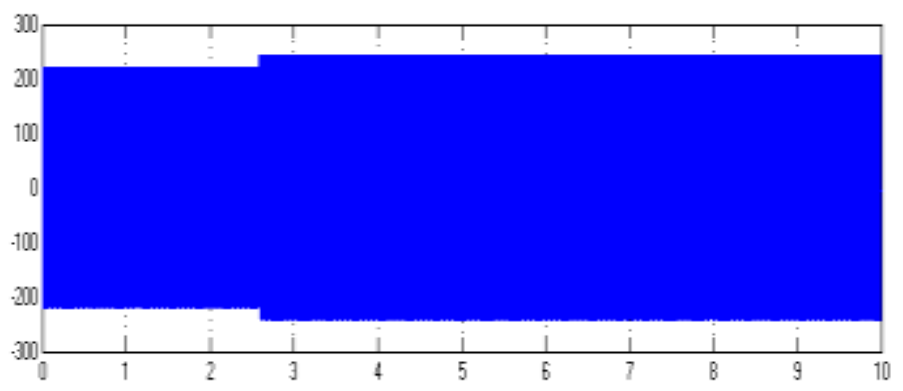

Fig 7: Input voltage(time $\mathrm{v}_{\mathrm{s}}$ voltage)
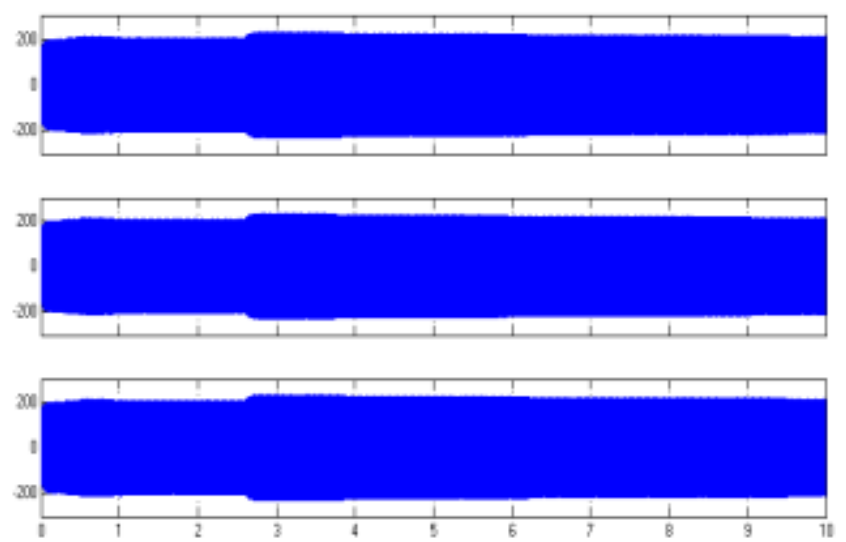

Fig 8: Outputvoltage (time $v_{\mathrm{s}}$ voltage) 


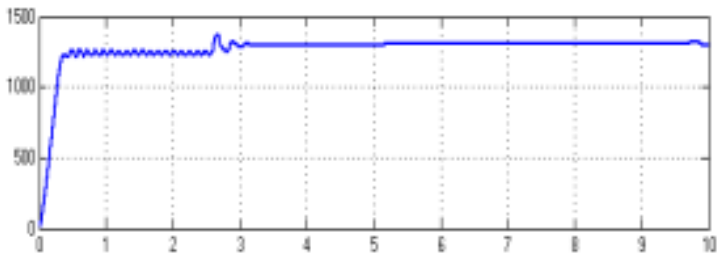

Fig 9: Motor speed

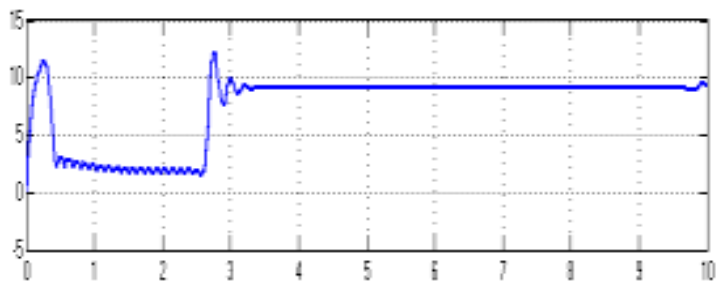

Fig 10: Motor Torque

2 a)Simulink model of Closed loop system with PI controller

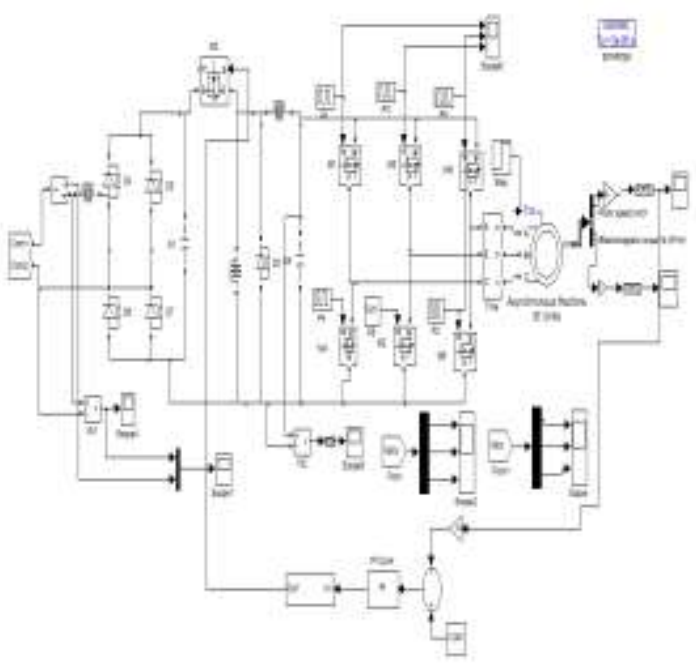

Fig 11: Simulink model of closed loop v/f control of induction motor with PI controller

\section{2b)simulink results}

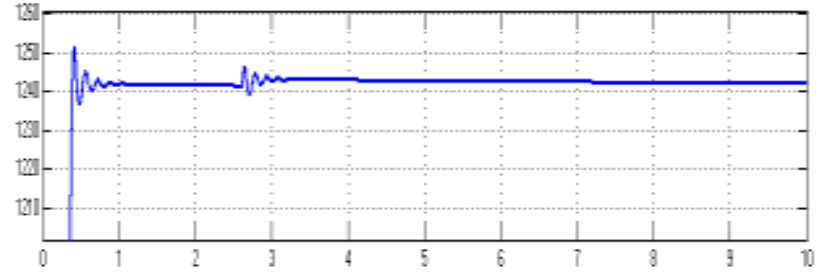

Fig 12: Motor speed

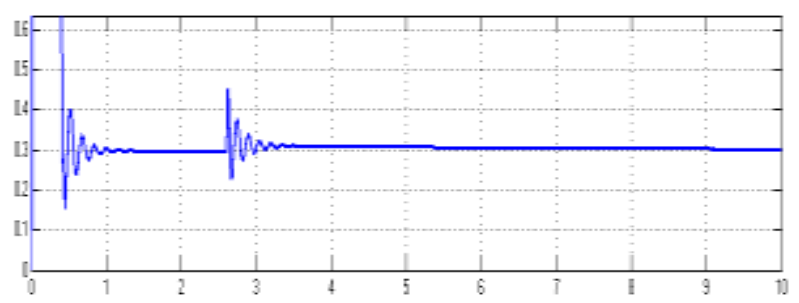

Fig 13: Motor Torque 


\section{3 ) Simulink results with fuzzy logic controller}

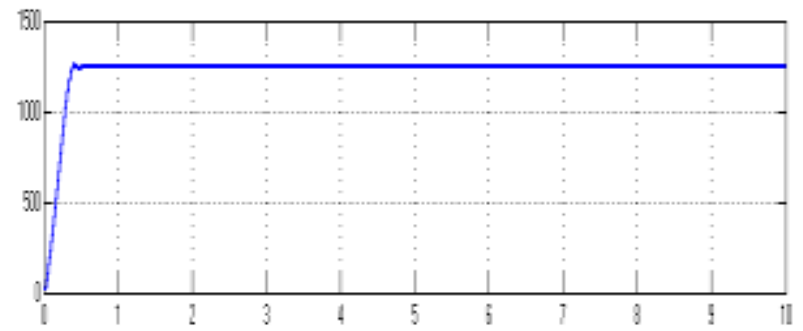

Fig 14: Motor speed

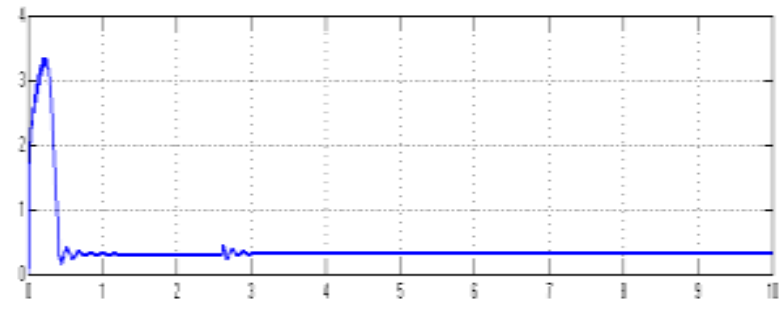

Fig 15: Motor Torque

4)Simulink results with Hysteresis controller

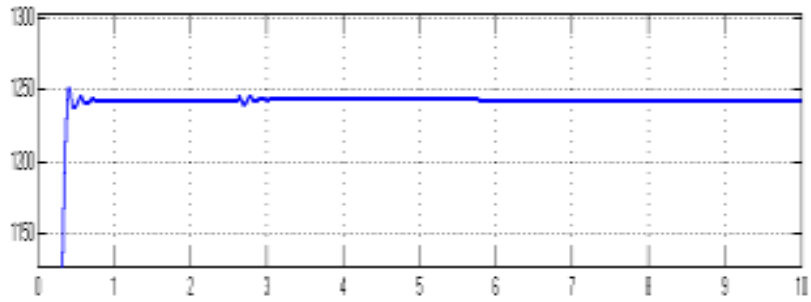

Fig 16: Motor speed

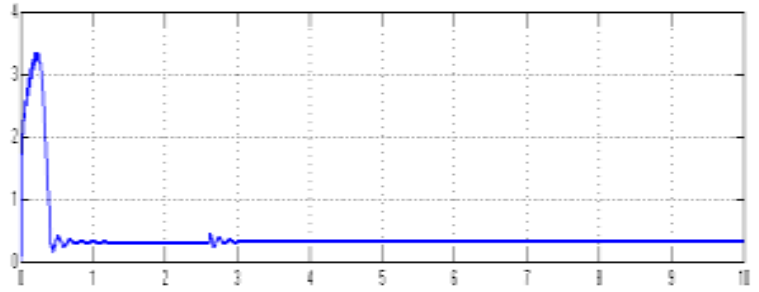

Fig 17: Motor Torque

Table-1 Time domain parameters

\begin{tabular}{|l|l|l|l|l|}
\hline Controller & Rise time $(\mathrm{s})$ & Peak time (s) & $\begin{array}{l}\text { Setting } \\
\text { time }(\mathrm{s})\end{array}$ & $\begin{array}{l}\text { Steady state } \\
\text { error (RPM) }\end{array}$ \\
\hline PI & 2.7 & 2.73 & 3.3 & 2.3 \\
\hline Hysteresis & 2.6 & 2.61 & 3.1 & 1.2 \\
\hline FLC & 0.3 & 0 & 0.4 & 0.7 \\
\hline
\end{tabular}

\section{Conclusion}

A novel voltage controlof ZETA converter fed induction motor difficulty. Speed manipulate using volts in keeping with hertz control is mentioned and is proven through simulations. A sensor much less operation minimizes the device complexity and reduces the price of general system. DC to DC operation of ZETAconverter improves the nice of energy supplied to the motor. ZETA converter can perform both step up as well as step down operation relying at the time for which gate is precipitated. Electricity factor of the overall device has improved. The voltage and modern profile fulfill diverse voltage and current requirements. The velocity of induction motor is found to be regulated within the stipulated tiers. Torque ripples are minimized by means of the closed loop operation of volts per hertz control. TheFLC system is able to supplying suitable torque- slip characteristics of the motor. 


\section{References}

[1]. S. Singh and B. Singh, "Voltage controlled PFC ZETA converter based BLDC MOTOR drive for an air-conditioner," 2010 International Conference on Industrial and Information Systems (ICIIS), pp.550-555, 29th July 2010- 1st Aug. 2010.

[2]. Bhim Singh, B.P.Singh and SanjeetDwivedi, "AC-DC ZETA Converter for Power Quality Improvement of Direct Torque Controlled PMSM Drive”, Korean Journal of Power Electronics, Vol. 6, No. 2, pp.146-162, April 2006.

[3]. J. Uceeda, J. Sebastian and F.S. Dos Reis, "Power Factor Pre regulators Employing the Flyback and ZETA Converters in FM Mode”, in Proceedings of IEEE CIEP'96, 1996, pp.132-137.

[4]. D.C. Martins, "ZETA Converter Operating in Continuous Conduction Mode Using the Unity Power Factor Technique", in Proceedings of IEE PEVSD'96, 1996, pp.7-11.

[5]. Paul P. Acarnley and John F. Watson, "Review of Position-Sensorless Operation of Brushless Permanent-Magnet Machines", IEEE Transactions on Industrial Electronics, Vol. 53, no. 2, April 2006.

[6]. James P. Johnson, M. Ehsani and YilcanGuzelgunler, "Review of Sensorless Methods for Brushless DC" Industry Applications Conference,

34th IAS Annual Meeting, 1999, Vol. 1, pp. 143-150.

[7]. Niculescu, Elena, DorinaMioara-Purcaru, Marius-Cristian Niculescu, Ion Purcaru and Marian Maria, "A simplified steady-state analysis PWM Zeta converter", In WSEAS International Conference. Proceedings. Mathematics and Computers in Science and Engineering, edited by N.E. Mastorakis, V. Mladenov, Z. Bojkovic, S.Kartalopoulos, A. Varonides, and M. Jha, no. 13.,World Scientific and Engineering,2009.

[8]. Wu, Tasi-Fu, and Yu-Kai Chen, "Modelling PWM DC/DC converters out of basic converter units", Power Electronics, IEEE Transactions on 13, no. 5 (1998): 870-881

[9]. Kochcha, Pijit and SarawutSujitjorn, "Isolated zeta converter: principle of operation and design in continuous conduction mode", WSEASTransactions on Circuits and Systems 9, no. 7 (2010): 483-492.

[10]. K. Singh, and A. G. Rao, "Overview of control Techniques for DC-DC converters", Research Journal EngineeringSciences ISSN 2278 (2013): 9472.

[11]. V. Bist and B. Singh, “A Reduced Sensor PFC BL-Zeta Converter Based VSI Fed BLDC Motor Drive ,” Electric Power System Research, vol.98, pp. 1118, May 2013.

[12]. Krishnan, R.:'Electric motor drives: modeling, analysis and control' (Pearson Education, India, 2001)

[13]. Uceeda, J., Sebastian, J., Dos Reis, F.S.: 'PF preregulatorsemploying the flyback and zeta converters in FM mode'. Proc. IEEE CIEP'96, 1996, pp. 132-137

[14]. Martins, D.C.: 'Zeta converter operating in ccmusing the unity power factor technique'. Proc. IEE PEVSD'96, 1996, pp. $7-11$ 